\title{
Great Expectations
}

\section{-Narratives and the Elicitation of Aesthetic Chills}

\author{
Felix Schoeller ${ }^{1}$, Leonid Perlovsky ${ }^{2 *}$ \\ ${ }^{1}$ Department of Media, Cognition and Communication, University of Copenhagen, Copenhagen, Denmark \\ ${ }^{2}$ Department of Psychology, Northeastern University, Boston, MA, USA \\ Email: "Iperl@rcn.com
}

Received 13 October 2015; accepted 26 December 2015; published 29 December 2015

Copyright (C) 2015 by authors and Scientific Research Publishing Inc.

This work is licensed under the Creative Commons Attribution International License (CC BY).

http://creativecommons.org/licenses/by/4.0/

(c) (i) Open Access

\begin{abstract}
We clarify the relation between the perception of narratives and aesthetic emotions by relating them to mechanisms of knowledge-acquisition. Stories elicit emotions by diverging from expectations one may formulate on the basis of their properties. The greater the divergence, the stronger the emotion. Models of emotions, expectations, and knowledge-acquisition are briefly presented. We relate them to research pertaining to narrative structures and provide a mathematical description for aesthetic emotions. We conclude by underlining the fundamental role played by aesthetic emotions in the workings of the human mind.
\end{abstract}

\section{Keywords}

Emotions, Aesthetic Chills, Expectations, Knowledge, Narratives, Meaning

\section{Introduction}

Stories count among some of the most admirable thought structures through which we can reach a better understanding of ourselves and of the world around us. They inform our reality and enrich our experience with meaning. As a consequence of this, it is not an odd thing to do than to expect from a master storyteller to tell us about such fundamentals as the actions of our ancestors or the meaning of life. Humans have long used folktales to transmit their knowledge throughout generations and children find great ease in the understanding of narratives. Since Tulving's pioneering works (Tulving, 1972), research on the mechanics of episodic memory or that of event-segmentation have shed some light on these ancient mysteries (e.g., Goldman, Graesser, \& van der Broek, 1999; Zacks \& Tversky, 2001; Schoeller, 2014; Anderson, 2015). Still, one of the main theoretical issues with stories (often discussed in analytic philosophy as the paradox of fiction) remains the fact that they can success-

*Corresponding author. 
fully elicit emotions.

To clarify this issue, we have carefully studied the problem of aesthetic chills (Schoeller, 2015a, 2015b). Chills are a muscular phenomenon best described as the sensation of coldness created by a rhythmic oscillating tremor of skeletal muscles. Aesthetic chills refer to an event when this process is unrelated to external changes in temperature level and associated with a highly positive hedonic process. In the course of an explorative study, we asked sixty participants (Bachelor of Science from the University of Copenhagen, 30f; age: 20 - 33; $\mathrm{m}=$ 22.77) what it felt like to experience chills in the course of viewing a narrative film. The exact protocol for the study is described elsewhere (Schoeller, in press). Repeatedly, our subjects underlined that chills were related to the realization of highly expected events. This is best exemplified in the following descriptions provided by our subjects (we have not modified the spelling mistakes):

- When an anticipated scene that the movie has led up to finally happens.

- When someone achieves a difficult goal or pain leads to pleasure in the end.

- When the past and the present filter together in a magnificent spin.

- When the weight of everything is released.

Aesthetic chills are known to be often elicited by tonal music (see, inter alios, Harrison \& Loui, 2014) and the role of expectations in music appreciation has been underlined in (Meyer, 1959; Huron, 2006). The present article investigates further the role of viewers' expectations in the occurring of narrative chills. First, we discuss the relation between expectations, emotions and narrative structures then we extend our inquiry into the problem of natural curiosity and knowledge-acquisition. We conclude by underlining the fundamental role played by aesthetic emotions in the workings of the human mind.

\section{Narrative Structures and Emotional Processes}

Stories elicit emotions by diverging from expectations one may formulate on the basis of their properties. David Hume was the first to point out the proportionality relationship at stake in this process: the greater the divergence, the stronger the emotion (Hume, 1757). But why is it that subjects expect something else? How is it that top-down representations differ significantly from the bottom-up signals they are suppose to match? In lower animals, a simple answer to this problem is to say that the amplitude of divergence depends on what the organism requires to survive, on what the animal needs. As noted by Montagu (1950), needs are best described as "reductors" of physiological tensions, urges which lead to a state of homeostasis (on the relation between emotion and fever see also Briese \& Cabanac, 1980; Cabanac, 2002). In humans, universal needs translate into particular practices, techniques and cultures (Malinowski, 1945). This might explain the presence of aesthetic chills in artistic, scientific and religious contexts alike (Schoeller, 2015b).

One way to describe emotions is to situate them in the flow of information processing. When incoming (bottom-up) sensory signals do not match the existing (top-down) mental models, an orientation response occurs and the strength of this response is a function of the amount of mismatch (Sokolov, 1963; Simonov, 1986; Pribram, 1971). This was formalized mathematically by the neurophysiologist Simonov in the second half of the twentieth century. Simonov accounts for the quantity and the quality of an emotional episode by laying out a rule for its development. This rule can be formalized in the form of the following structural equation:

$$
E=f\left[N\left(I_{n}-I_{a}\right)\right]
$$

where $E$ is emotion; $N$ is the magnitude and quality of actual need; $\left(I_{n}-I_{a}\right)$ is the evaluation of probability of satisfying the need; $I_{n}$ is information on means predictably necessary for satisfying the need; $I_{a}$ is information on means that the subject has available to him at the given moment.

It is important to underline that the "amount" of emotion is not to be considered in terms of energy but in terms of expectancies challenged by the incoming signal. "Amount" is thus viewed as match and mismatch between configurations, not as an arousal or energy available to the cognitive system during the episode (Pribram, 1967). A similar view is advocated by Grossberg, in his model, affective signals have an evaluative role: they influence the formation of internal representation of objects and events according to their role in satisfying needs (Grossberg, 1971, 1982). Another model, specifically designed for modeling aesthetic emotions is that of Perlovsky (2006). We will discuss these mathematical theories in depth below but let us outline from the start that aesthetic chills and chill-eliciting stimuli are extremely interesting events for these research since they describe the emergence of an equilibrium. 
Consider the particular case of stories. Equilibria play an essential symbolic role in narratological architectonics. Chill-inducing scenes take place in the last third of the plot; what Aristotle (1984) refers to as the third act and Freytag (1897) describes as denouement. The Russian formalist Propp (1968) talks about "the hero's return" and Todorov (1969) "a final equilibrium". Consider a story about a peasant who is madly in love with a princess. In an ideal world, the peasant's goal would be realized and he and the princess would be together; but social classes interfere with this ideal state of the story world and correspondingly the viewer's expectancies are challenged by the film. There exist a certain amount of mismatch between the configurations of these expectancies (in informational terms: $I_{n}>I_{a}$ ). This might elicit negative emotions such as anger, frustration, and sadness. Maybe, after some unfortunate hunting accident, the king encounters the peasant and takes him under his protection (in informational terms, progress has been made toward the goal and so: $I_{n} \leq I_{a}$ ). This might elicit positive emotions such as contentment, excitement. Later on in the process, a war might rage and the peasant has to defend his king on the battlefield where he gets seriously injured (in informational terms: $I_{n} \gg I_{a}$ ). The viewer might experience emotions such as fear, concern, and tension. At this stage, the properties of the story world diverge more from the ideal state of affairs than in the opening and probabilities for the peasant to be with the princess are extremely low. As a consequence of this divergence more complex computations are required in order to assess the probability, under these new given conditions, for the peasant to be with the princess. Again, the greater the distance, the more demanding the process, the stronger the emotion. Chills are usually elicited at the climax of the film. When the impossible is made necessary and the peasant comes back to the castle after a long absence to be reunited with the princess (in informational terms: $I_{n} \approx I_{a}$ ). This explains why in their phenomenological descriptions most subjects mention a strong relaxation and a calming effect (Schoeller, in press).

\section{Curiosity and Knowledge-Acquisition}

Simonov' framework does not specify how to compute involved amounts of information, it does not permit to take into account "the magical ring" which reunites the peasant and the princess, though it can serve as a useful heuristic principle of research. Considerable progress has been made since Simonov's model in terms of computational account for mental activity. More recent theoretical frameworks help overcome some of the most evident difficulties posed by the expression (1)—namely, quantifying needs. A more contemporary mathematical theory of aesthetic emotions (Perlovsky, 2001, 2006; Perlovsky, Deming, \& Ilin, 2011) relates them to knowledge-acquisition and curiosity. This theory describes knowledge-acquisition as a maximization of the similarity between events perceived in the world and their mental representations, the knowledge instinct (KI). The similarity is given by:

$$
L=\left\{\prod_{n}\left[\sum_{m} l(X(n) \mid M(m))\right]\right\} .
$$

Here $X(n)$ is information available about external events (bottom-up signals); $M(m)$ are mental models of these events (top-down models); $l(X(n) \mid M(m))$ are similarities between events $n$ and models $m$; sum over $m$, $\Sigma$ takes into account all models and product over $n$, $\Pi$ takes into account all events. This formulation is an extension of the Grossberg-Levine's theory of drives and emotions (Grossberg \& Levine, 1987), where drives are modeled as internal sensors measuring vital bodily parameters and indicating their safe ranges. When a parameter is outside its safe range, this information is transmitted by neural signals to decision-making parts of the brain initiating appropriate decisions and behavior. These neural signals are experienced internally as emotions and motivate behavior. A simple example would be that of blood glucose level, when the sugar concentration is below a certain level, it is felt as hunger and the subject devotes more attention to finding food. This framework is also useful for describing and understanding more complex emotions. Satisfaction of bodily needs and our very survival requires adequate understanding of the surrounding world. Events are perceived by matching mental representations to patterns distinguishable in our sensorial modalities (Grossberg, 1988; Kosslyn, 1994). One of the most fundamental drives is therefore that which guides such a process. KI is necessary to the improvement of the correspondence between mental models and the external world, its activity is described as maximization of the measure of similarity $L$ introduced above. Similar to other drives, satisfaction and dissatisfaction of KI are perceived emotionally. These specific emotions can be measured as a change of the similarity $L$ in the process of learning and knowledge-acquisition — that is, as a progress made towards adequate representations $M(m)$. At the end of this natural process of maximization of similarity (at its maximum), derivatives ap- 
proximate zero. Aesthetic chills correspond to the mathematical description $(X(n) \approx M(m))$, where $L$ tends towards its maximum value and the rate of change of the similarity function reaches a peak value (a local peak). Note that a similar description fits an event where chills are elicited by a highly negative cue, when the similarity reaches a minimum — in both cases, the derivatives of the similarity tend toward zero.

\section{Conclusion}

Narrative chills correspond to an event where an answer to the dramatic question (e.g., will the hero reach his goal?) has been provided to the viewer (reader, listener, etc.). They often occur when narrative tension reaches its peak and the plot resolves itself. From that point on, the spectator possesses knowledge of the film and is able to summarize it (Schoeller, 2014). She is now able to answer the question: what is the meaning of this film? what is this story about? Further research is needed to determine the modalities of such a process. Empirical studies of the relations between knowledge, meaning, and aesthetic emotions are rare but necessary to our understanding of what humans perceive as the most important domains of their lives (the content of the categories at the top of the cognitive hierarchy and their corresponding emotions). We proposed that one of these entities might be the meaning of life and encourage researchers to test this hypothesis in further experimentation. The narratology of chill-eliciting scenes and the role of expectations in the elicitation of chills are coherent with results obtained by previous studies about the neurobiology of music-induced chills. The latter were demonstrated to be mediated by opioid receptors and mesolimbic dopaminergic neurons involved in reward and emotion (Blood \& Zatorre, 2001). We get rewarded because we have understood the film all along, expectations formed on the basis of prior situations proved correct, higher-intermediate representations were built up, and they proved justified, useful and functional. Ceteris paribus, the vital need for cognition is temporarily satisfied.

\section{References}

Anderson, T. (2015) From Episodic Memory to Narrative in a Cognitive Architecture. Proceedings of the 6th Workshop on Computational Models of Narrative (CMN'15), Atlanta, 1-11.

Aristotle (1984). The Complete Works (Translated by Barnes, J., Vol. I and II). Princeton: Princeton University Press.

Blood, A. J., \& Zatorre, R. J. (2001). Intensely Pleasurable Responses to Music Correlate with Activity in Brain Regions Implicated in Reward and Emotion. Proceedings of the National Academy of Sciences of the United States of America, 98, 11818-11823. http://dx.doi.org/10.1073/pnas.191355898

Briese, E., \& Cabanac, M. (1980). Emotional Fever and Salicylate. In: Z. Szelenyi, \& M. Szekely (Eds.), Satellite Symposium of the 28th International Congress of Physiological Sciences, Pécs (pp. 161-163). Oxford: Pergamon.

Cabanac, M. (2002). What Is Emotion? Behavioural Processes, 60, 69-83. http://dx.doi.org/10.1016/S0376-6357(02)00078-5

Freytag, G. (1897). Die Technik Des Dramas (Techniques of Drama). Volume 14 of His Gesammelte Werke, 2. Auflage, S. Hirzel, Leipzig.

Goldman, Graesser, \& van der Broek (1999). Narrative Comprehension, Causality, and Coherence. Mahwah, NJ: Lawrence Erlbaum.

Grossberg, S. (1971). Embedding Fields: Underlying Philosophy, Mathematics and Applications to Psychology, Physiology, and Anatomy. Journal of Cybernetics, 1, 28-50. http://dx.doi.org/10.1080/01969727108545828

Grossberg, S. (1982). The Processing of Expected and Unexpected Events during Conditioning and Attention: A Psychophysiological Theory. Psychological Review, 89, 529-572. http://dx.doi.org/10.1037/0033-295X.89.5.529

Grossberg, S. (1988). Nonlinear Neural Networks: Principles, Mechanisms, and Architectures. Neural Networks, 1, 17-61. http://dx.doi.org/10.1016/0893-6080(88)90021-4

Grossberg, S., \& Levine, D. S. (1987). Neural Dynamics of Attentionally Modulated Pavlovian Conditioning: Blocking, Interstimulus Interval, and Secondary Reinforcement. Applied Optics, 26, 5015-5030. http://dx.doi.org/10.1364/AO.26.005015

Harrison, L., \& Loui, P. (2014). Thrills, Chills, Frissons, and Skin Orgasms: Toward an Integrative Model of Transcendent Psychophysiological Experiences in Music. Frontiers in Psychology, 5, 790. http://dx.doi.org/10.3389/fpsyg.2014.00790

Hume, D. (1898/1757). Four Dissertations. In T. H. Green, \& T. H. Grose (Eds.), The Philosophical Works of David Hume (1-240). London: Longmans, Green, and Co.

Huron, D. B. (2006). Sweet Anticipation: Music and the Psychology of Expectation. Cambridge, MA: MIT Press. 
Kosslyn, S. M. (1994). Image and Brain. Cambridge, MA: MIT Press.

Malinowski, B., \& Kaberry, P. M. (1945). The Dynamics of Culture Change. New Haven, CT: Yale University Press.

Meyer, L. (1959) Some Remarks on Value and Greatness in Music. The Journal of Aesthetics and Art Criticism, 17, 486-500. http://dx.doi.org/10.2307/428221

Montagu, A. (1950). On Being Human. New York: H. Schuman.

Perlovsky, L. (2006). Toward Physics of the Mind: Concepts, Emotions, Consciousness, and Symbols. Physics of Life Reviews, 3, 23-55. http://dx.doi.org/10.1016/j.plrev.2005.11.003

Perlovsky, L. I. (2001). Neural Networks and Intellect: Using Model Based Concepts. New York: Oxford University Press.

Perlovsky, L.I., Deming R.W., \& Ilin, R. (2011). Emotional Cognitive Neural Algorithms with Engineering Applications. Dynamic Logic: From Vague to Crisp. Heidelberg: Springer. http://dx.doi.org/10.1007/978-3-642-22830-8

Pribram, K. H. (1967). The New Neurology and the Biology of Emotion: A Structural Approach. American Psychologist, 22, 830-838. http://dx.doi.org/10.1037/h0025031

Pribram, K. H. (1971). Languages of the Brain: Experimental Paradoxes and Principles in Neuropsychology. Englewood Cliffs, NJ: Prentice-Hall.

Propp, V. I. (1968). Morphology of the Folktale (2nd ed., Vol. 9). Austin: University of Texas Press.

Schoeller, F. (2014). La mécanique cognitive des films narratifs [The Cognitive Mechanics of Narrative Films]. Paris: École des Hautes Études en Sciences Sociales.

Schoeller, F. (2015a) Knowledge, Curiosity, and Aesthetic Chills. Frontiers in Psychology, 6, 1546. http://dx.doi.org/10.3389/fpsyg.2015.01546

Schoeller, F. (2015b). The Shivers of Knowledge. Human and Social Studies, 4, 26-41. http://dx.doi.org/10.1515/hssr-2015-0022

Schoeller, F. (in Press). Curiosity Traits and Epistemic Behavior Predict for Aesthetic Chills. Currently under Review (Copy on File with Author).

Simonov, P. V. (1986). The Emotional Brain: Physiology, Neuroanatomy, Psychology, and Emotion. New York: Plenum Press. http://dx.doi.org/10.1007/978-1-4899-0591-8

Sokolov, E. N. (1963). Perception and the Conditioned Reflex. Oxford: Pergamon Press.

Todorov, T. (1969). Grammaire du Décaméron [Grammar of the Decameron]. Approaches to Semiotics, Vol. 3, The Hague: Mouton.

Tulving, E., \& Donaldson, W. (Eds.) (1972). Organization of Memory. New York: Academic Press.

Zacks, J. M., \& Tversky, B. (2001). Event Structure in Perception and Conception. Psychological Bulletin, 127, 3-21. http://dx.doi.org/10.1037/0033-2909.127.1.3 